ISSN1027-5495. Functional Materials, 24, No.1 (2017), p. 184-189

doi:https://doi.org/10.15407/fm24.01.184

(C) 2017 - STC "Institute for Single Crystals"

\title{
New method for estimating the grounding reliability test of aircraft cable shield
}

\author{
Hongxu Zhao', Geng Zhang ${ }^{1}$, Yongyun Wang', Qian Wang ${ }^{2}$ \\ ${ }^{1}$ Department of Electronic Information and Automation, Civil Aviation \\ University of China, Tianjin 300300, China \\ ${ }^{2}$ Department of Flight Techniques, Civil Aviation University of China, \\ Tianjin 300300, China
}

Received November 30, 2016

\begin{abstract}
We investigated a new method based on electromagnetic induction technique is proposed for reliability test of the grounding connection, and a test setup is built for experiment. As proven by the experimental results, the proposed method can provide a wide measurement rang and sufficiently high accuracy, to measure the loop resistance and joint resistance.

Keywords: cable shield; grounding reliability; electromagnetic induction; loop resistance; joint resistance; shielding effectiveness

Предложен новый метод для оценки надежности заземления бортовой аппаратуры летательных аппаратов, основанный на измерении электромагнитной индукции. По сравнению с традиционным методом, данный метод не требует отсоединения кабельных жгутов. Создана испытательная установка для проверки точности измерений такого метода. Результаты измерений показали достоверность данного метода. Диапазон измерений [1m $\Omega, 4000 \mathrm{~m} \Omega$ ], относительная ошибка меньше чем $5 \%$.
\end{abstract}

Новий метод оцінки надійності заземлення авіаційних кабельних джгутів. Хунгху Чжао, Ген Чжан, Юнгун Ван, Цянь Ван

Запропоновано новий метод для оцінки надійності заземлення бортової апаратури літальних апаратів, заснований на вимірюванні електромагнітної індукції. У порівнянні з традиційним методом, даний метод не вимагає від'єднання кабельних джгутів. Створеновипробувальну установку для перевірки точності вимірювань такого методу. Результати вимірювань показали достовірність даного методу. Діапазон вимірювань [1m $\Omega, 4000 \mathrm{~m} \Omega$ ], відносна помилка менше ніж 5\%.

\section{Introduction}

Fly by wire flight control system is widely used on the modern airplanes to promote the integration of all kinds of avionics systems. As the main carrier of the information exchange, the avionics data bus plays an important role in ensuring the reliability and integrity of the transmitted data. But unpredictable conditions, such as lightning and HIRF challenges the quality of the data transmission in the way of electromagnetic interference [1, 2].The protection from such complex electromagnetic interference is to ground both the ends of the cable shield to the airframe, in such way the cable shield, airframe and the connector in between builds a conductive loop, which circulates the electrical currents generated by the lightning or HIRF to the ground without affecting internal transmitting data. The reliability of the grounding connection depends heavily on the resistance of the shield it self, any defect 
on the shield larges its resistance and further affect the grounding reliability. In addition, the reliability of the grounding connection maybe suffered from the poor installation of the connector as well, since the joint resistance of the connector is also part of loop resistance [3-5].

The traditional method to test cable shield has an inevitable drawback that, the shielded cable has to be disassembled from the airframe first, and then the shield can be tested by any accurate resistance-measuring instrument as the way how regular resistor is tested. Although such method provides very good accuracy in measuring the resistance of the shield itself, but due to the fact that the cable need to be re-installed after the test, wherein poor installation might happen, which could turn into an unacceptable joint resistance. As explained above, joint resistance is part of the shield loop resistance, so with an improperjoint resistance the shielding effectiveness

declines even if the shield itself is ideal [6, 7]. Based on the voltage-current vector method, using electromagnetic induction technique, a new method is proposed to test the loop resistance of the shield, with this method the shield can be tested "online", which means it is not necessary to disassemble the cable anymore.

\section{Algorithm of test method}

As shown in Fig.1, the cable shield, airframe and two connectors constitute the shield loop. A drive coupler is used to drive particular loop voltage on the shield, meanwhile another sense coupler collects the information of the loop current. At the end, the voltage-current vector method is applied to calculate the loop resistance. Assuming the airframe is in perfect condition, it has negligible resistance, which means the calculated loop resistance can be considered approximatively as the sum of the shield resistance and the joint resistance. With this assumption, as long as the measured loop resistance is lower than the constrain, both of the shield and the connection are safe. If the loop resistance exceeds the constrain, it indicates a fault occurs either on the shield or the connection, or even both of them. In order to locate the fault, two probes are used to detect the voltage across the connector, and voltagecurrent vector method is applied again to solve the joint resistance. Further based on the loop resistance and joint resistance, the fault can be found easily.

In order to induce particular loop voltage on the shield loop, an $\mathrm{AC}$ voltage signal $\mathrm{U}_{\mathrm{D}}(\mathrm{t})$ is put on the drive coupler. This signal can be described by Eq. (1), where the amplitude A is $5 \mathrm{~V}$,

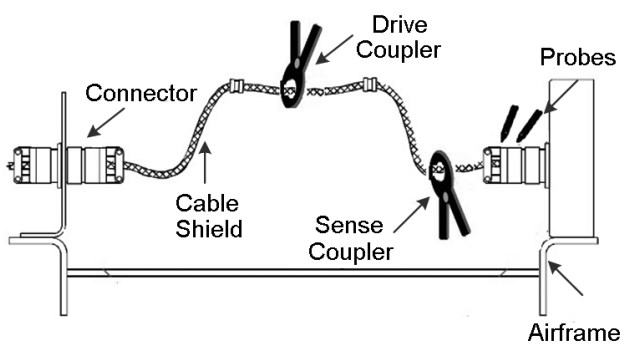

Fig. 1. Test Environment

the frequency $\mathrm{f}$ is $200 \mathrm{~Hz}$, and the initial phase is 0 degree.

$$
U_{D}(t)=A \sin (2 \pi f t+\theta)
$$

While the two couplers are clamped on the shield, induced loop voltage $\mathrm{U}_{\mathrm{L}}(\mathrm{t})$ and loop current $I_{L}(t)$ occurs on the shield loop, where the subscript L stands for loop. Since the frequency of the signals is only $200 \mathrm{~Hz}$, so these two signals can be easily captured by an acquisition module at $50 \mathrm{KHz}$.

After sampling, the continuous signals $\mathrm{U}_{\mathrm{L}}(\mathrm{t})$ and $I_{L}(t)$ turn into two sets of discrete signals $\mathrm{U}_{\mathrm{L}}(\mathrm{k})$ and $\mathrm{I}_{\mathrm{L}}(\mathrm{k})$, which are shown as following,

$U_{L}(k)=$

$=\left\{U_{L}(1), U_{L}(2), U_{L}(3), \cdots, U_{L}(n)\right\}, 1 \leq k \leq n$

$I_{L}(k)=$

$=\left\{I_{L}(1), I_{L}(2), I_{L}(3), \cdots, I_{L}(n)\right\}, 1 \leq k \leq n$

Afterwards, the Fast Fourier Transform is performed on the two discrete signals separately, while the size $\mathrm{N}$ of the process window is set to 5000. The solution of the FFT calculation for each signal is set of complex numbers, and each complex number corresponds to one frequency component, which is shown as the following equations,

$$
\begin{aligned}
& U_{L F}(K)=\operatorname{FFT}\left(U_{L}(k)\right)= \\
& =U_{L F R}(K)+j U_{L F X}(K), \quad 1 \leq K \leq N \\
& I_{L F}(K)=\operatorname{FFT}\left(I_{L}(k)\right)= \\
& =I_{L F R}(K)+j I_{L F X}(K), \quad 1 \leq K \leq N
\end{aligned}
$$

The subscript $\mathrm{F}$ appears in above equations stands for FFT, and R stands for real part of the complex number where $\mathrm{X}$ stands for imaginary part. According to Eq. (6), the index $\mathrm{K}$ of the complex number that corresponds to $200 \mathrm{Hzcan}$ be calculated.

$$
f_{K}=\frac{(K-1)}{N} f_{s}
$$

When $\mathrm{f}_{\mathrm{K}}$ is $200 \mathrm{~Hz}, \mathrm{~N}$ is 5000 and $\mathrm{f}_{\mathrm{S}}$ is $50 \mathrm{KHz}$, the $\mathrm{K}$ equals to 21 . So the loop impedance $\mathrm{Z}_{\mathrm{L}}$ of the shield can be calculated by following equation, 


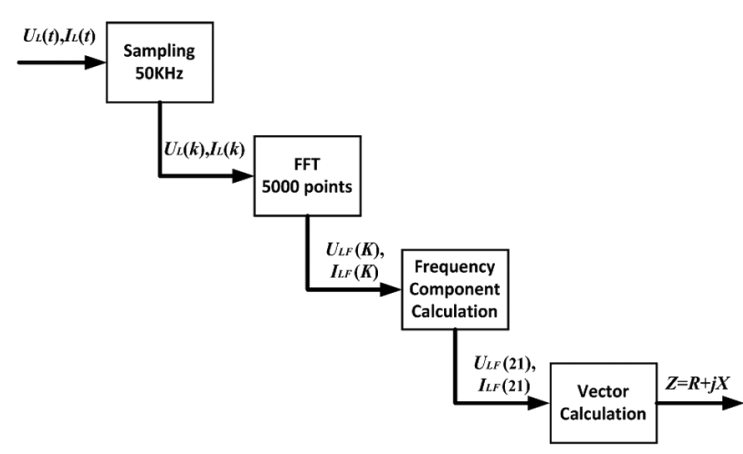

Fig. 2. Resistance calculation procedure

$$
Z_{\mathrm{L}}=\frac{U_{L F}(21)}{I_{L F}(21)}=\frac{U_{L F R}(21)+j U_{L F X}(21)}{I_{L F R}(21)+j I_{L F X}(21)}
$$

The calculated loop impedance is also a complex number, and the real part is the loop resistance $\mathrm{R}_{\mathrm{L}}$, as shown in the following equation,

$$
\begin{aligned}
& R_{\mathrm{L}}=\mathrm{RE}\left(Z_{L}\right)= \\
& =\frac{U_{L F R}(21) I_{L F R}(21)+U_{L F X}(21) I_{L F X}(21)}{I_{L F R}(21)^{2}+I_{L F X}(21)^{2}}
\end{aligned}
$$

The procedure of the resistance calculation is shown in Fig.2.

\section{Architeture of test setup}

The block diagram of the entire system is shown in Fig.3. It mainly consists of four parts, which are human machine interface, control platform, auxiliary circuit and test tools. The human machine interface provides the operator with a graphical user interface for monitoring the system's state and setting operating parameters. The control platform comprises one processing unit and two analog I/O modules. The processing unit is responsible for logical control, data processing and I/O modules configuration. According to the functionality of each I/O modules, they are named generation module and acquisition module respectively.

Two types of test tools are employed, the couplers are used for loop resistance measurement, and the probes are used for joint resistance measurement. Ideally, the output signal of the test tools should be fed to the acquisition module directly, but the range of the output signal is too wide and additionally the sampling accuracy is necessarily to be high as well, so the acquisition module is not capable to process the signal directly. For this reason, an auxiliary circuit is designed to process the signal before the control platform starts to sample.

\section{A.Control Platform}

The block diagram of the control platform is shown in Fig.4. It is built based on NI product cRIO-9075 integrated system, which combines a real-time processor and a reconfigurable FPGA within the same chassis. The real time processor can provide precise timing and stability, so it is used for logical control and data logging. The FPGA communicates with real time processor by PCI bus, but it connects to the I/O modules directly rather than any kinds of bus, and it is used to configure, drive and synchronize all the connected I/O modules. One of the used I/O module is a 24-bit analog input module with $\pm 10 \mathrm{~V}$ simultaneous sampling range and $50 \mathrm{kS} / \mathrm{s}$ sampling rate. The other one is a $100 \mathrm{kS} / \mathrm{s}$ analog output module, which has $\pm 10 \mathrm{~V}$ range and 16-bit resolution.

\section{B.Test Tools}

The two couplers are identical in structure but different in functionalities. Both of them have two coils and one magnetic core inside, as shown in Fig.5. For each coupler, the two coils have different number of turns for different purposes, one of them is 1000 turns and the other is 10 turns. During the measurement, the two couplers are clamped on the shield loop, as

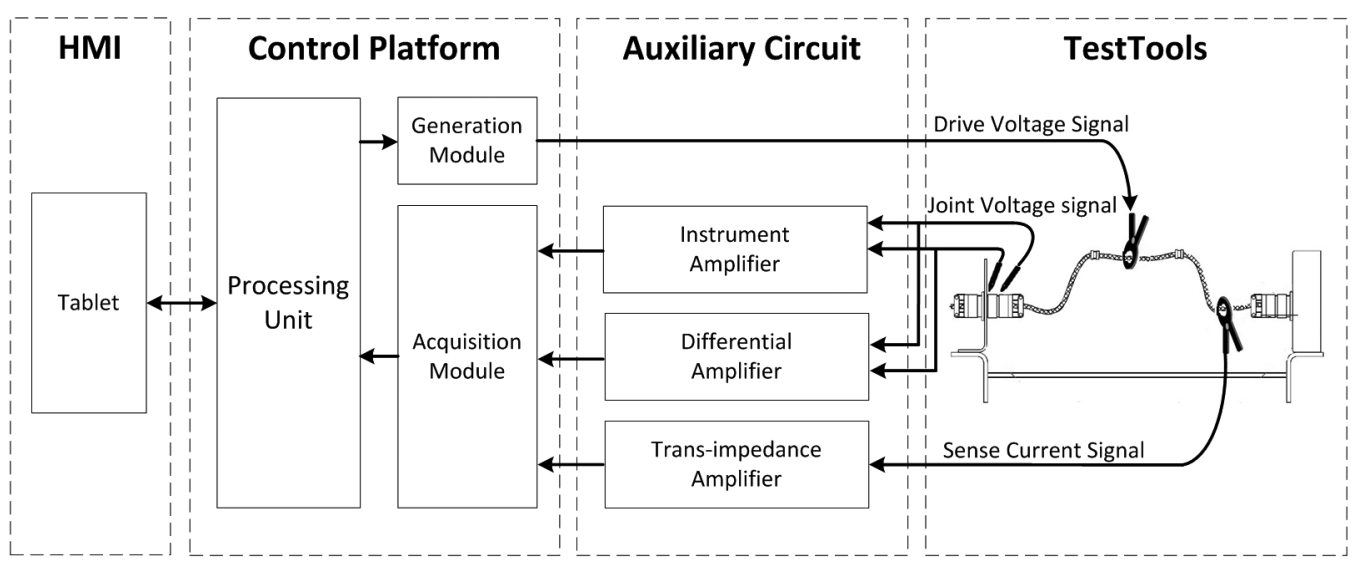

Fig. 3. Block diagram of test setup 


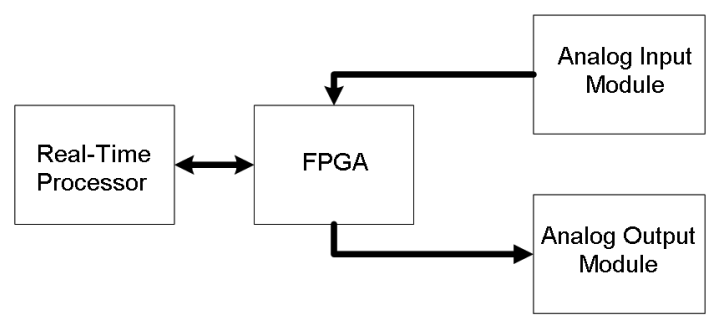

Fig. 4. Block diagram of control platform

a consequence the 1000 turns coil and the magnetic core of the drive coupler and the shield loop forms a structure as transformer. Since the shield loop only has one turn, so if the driving voltage $\mathrm{U}_{\mathrm{D}}$ is applied on the 1000 turns coil, consequently there should be a 1000 times less loop voltage $\mathrm{U}_{\mathrm{t}}$ induced on the shield loop.

Similarly, the 1000 turns coil and the magnetic core of the sense coupler and the shield loop forms another transformer structure, which turns ratio is $1: 1000$. Consequently, the current ratio between output current $\mathrm{I}_{\mathrm{S}}$ and loop current $I_{L}$ is inversely proportional to the turns ratio. At the end, assuming both of the coupler are fully closed and there is no flux leakage, then the loop impedance $\mathrm{Z}_{\mathrm{L}}$ can be calculated as the following equation,

$$
Z_{L}=\frac{U_{L}}{I_{L}}=\frac{U_{D} \times \frac{1}{1000}}{I_{S} \times \frac{1000}{1}}
$$

When either of the couplers is not fully closed, there will be flux leakage flow out of the magnetic core, so that the voltage ratio and current ratio will not be as same as the turns ratio any more, which possibly cause a measurement error at the end. In order to provide protection from such problem, inside the coupler there is another 10 turns coil as introduced above. Ideally, the output voltage $U_{S}$ of this extra coil should be 100 times less than the $U_{D}$ because of the turns ration. Therefore, whenever the measured $U_{\mathrm{S}}$ deviates from the theoretical value, it proves the coupler is not fully closed [8].

The probes are used for joint impedance measurement, but the two couplers are necessarily to be clamped on the shield as well during the measurement. One of the probe touches the cable connector while the other probe touches the airframe, the difference from the two probes is the joint voltage $\mathrm{U}_{\mathrm{J}}$, and the joint impedance is calculated as Eq. (10),

$$
Z_{J}=\frac{U_{J}}{I_{L}}=\frac{U_{J}}{I_{S} \times \frac{1000}{1}}
$$

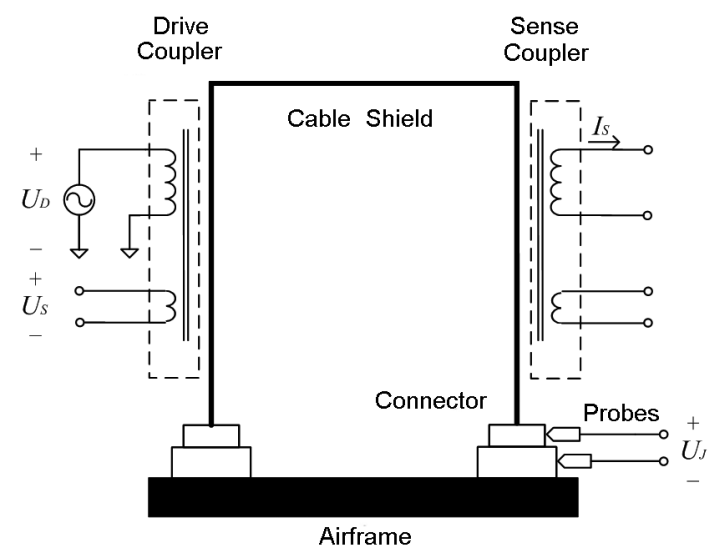

Fig. 5. Working principle of the test tools

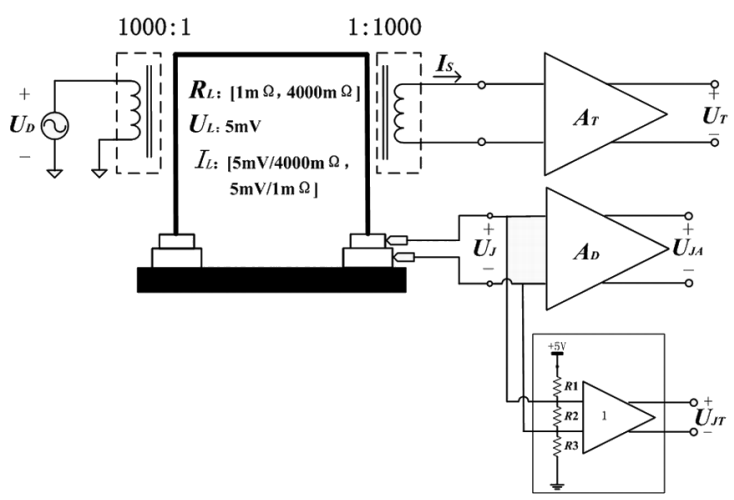

Fig. 6. Block diagram of auxiliary circuit

\section{Auxiliary Circuit}

As introduced in the beginning of the paper, an auxiliary circuit is designed to pre-process the output signals $I_{S}$ and $U_{J}$ of the test tools. More specifically, the auxiliary circuit comprises three sub-circuits, which are trans-impedance amplifier circuit, instrument amplifier circuit and differential amplifier circuit.

The trans-impedance amplifier circuit is used to convert the output current $\mathrm{I}_{\mathrm{S}}$ to voltage signal $\mathrm{U}_{\mathrm{T}}$, since the acquisition module is not capable to process current signal, as shown in the Fig.6. If the gain $\mathrm{A}_{\mathrm{T}}$ of the amplifier is set too high, while measuring low resistance shielding loop, the value of $U_{T}$ may exceed the sampling range of the acquisition module. If the gain $\mathrm{A}_{\mathrm{T}}$ is set too low, while measuring high resistance shielding loop, the $\mathrm{U}_{\mathrm{T}}$ may be inaccurate because of the sampling resolution of acquisition module [9]. Considering both constrains, the gain $\mathrm{A}_{\mathrm{T}}$ is set to 1000 at the end.

The joint voltage $U_{\mathrm{J}}$ is a differential signal, it is processed by an instrument amplifier circuit firstly, instead of going to the acquisition module directly. Within the instrument amplifier circuit, the differential signal is converted to single ended signal. The gain $A_{D}$ is set to 100 to satisfy the acquisition capability of the hardware. 
Hongxu Zhao et al. / New method for estimating the grounding ...

Table 1. Measurement result of the loop resistance

\begin{tabular}{|c|c|c|c|c|c|c|}
\hline & Nominal $/ \mathrm{m} \Omega$ & Test $1 / \mathrm{m} \Omega$ & Test $2 / \mathrm{m} \Omega$ & Test3/m $\Omega$ & Test4/m $\Omega$ & Test5/m $\Omega$ \\
\hline $\mathrm{R}_{\mathrm{L} 1}$ & 2.047 & 2.035 & 2.030 & 2.033 & 2.033 & 2.032 \\
\hline $\mathrm{R}_{\mathrm{L} 2}$ & 8.541 & 8.496 & 8.507 & 8.505 & 8.506 & 8.502 \\
\hline $\mathrm{R}_{\mathrm{L} 3}$ & 14.100 & 13.916 & 13.921 & 13.892 & 13.897 & 13.918 \\
\hline $\mathrm{R}_{\mathrm{L} 4}$ & 3659 & 3660 & 3670 & 3660 & 3660 & 3660 \\
\hline
\end{tabular}

Table 2. Measurement result of the joint resistance

\begin{tabular}{|c|c|c|c|c|c|c|}
\hline & Nominal/m $\Omega$ & Test1/m $\Omega$ & Test2/m $\Omega$ & Test3/m $\Omega$ & Test4/m $\Omega$ & Test5/m $\Omega$ \\
\hline $\mathrm{R}_{\mathrm{J} 1}$ & 0.500 & 0.509 & 0.506 & 0.506 & 0.506 & 0.508 \\
\hline $\mathrm{R}_{\mathrm{J} 2}$ & 4.997 & 5.061 & 5.056 & 5.0545 & 5.052 & 5.057 \\
\hline $\mathrm{R}_{\mathrm{J} 3}$ & 25.010 & 25.060 & 25.292 & 25.270 & 25.285 & 25.280 \\
\hline $\mathrm{R}_{\mathrm{J} 4}$ & 50.000 & 50.445 & 50.410 & 50.433 & 50.430 & 50.430 \\
\hline $\mathrm{R}_{\mathrm{J5}}$ & 3603 & 3620 & 3670 & 3680 & 3615 & 3620 \\
\hline
\end{tabular}

Considering the fact that there is huge amount of cables next to each other closely on the airplane, sometimes it is not easy to reach the testing point using the probes through all the cables. Hence, it is possible to have a fake contact of the probes and testing point, which definitely leads to a failure measurement. In order to avoid the occurrence of such case, a modified differential amplifier circuit is designed. A three-resistor ladder is put in front of the differential amplifier, and all three resistors have a big value in resistance. The most important resistor $R_{2}$ is in parallel with the joint. Ideally, the resistance of the joint is much lower than $R_{2}$, so depends on the contact of the probes and testing points, the voltage across $R_{\text {, }}$ could be very different [10]. In such way, bad contact from the probes can be warned before the measurement runs.

\section{Exeperiment and result}

As shown in Fig.7, four standard loop resistors and five joint resistors have been used for verification experiment, and all the resistor has been calibrated right before the experiment.

Each resistor has been measured for 10 times, and test results for loop resistance and joint resistance are listed in Table 1 and Table 2 , respectively.

In table I and table II, the subscript L indicates loop resistor and $\mathrm{J}$ indicates joint resistor. Comparing to the nominal value of each resistor, it can be concluded that the test setup is able to measure the loop resistance and joint resistance very accurately. In order to further evaluate the accuracy of this test setup, the relative error for each measurement is calculated as Eq. (11),

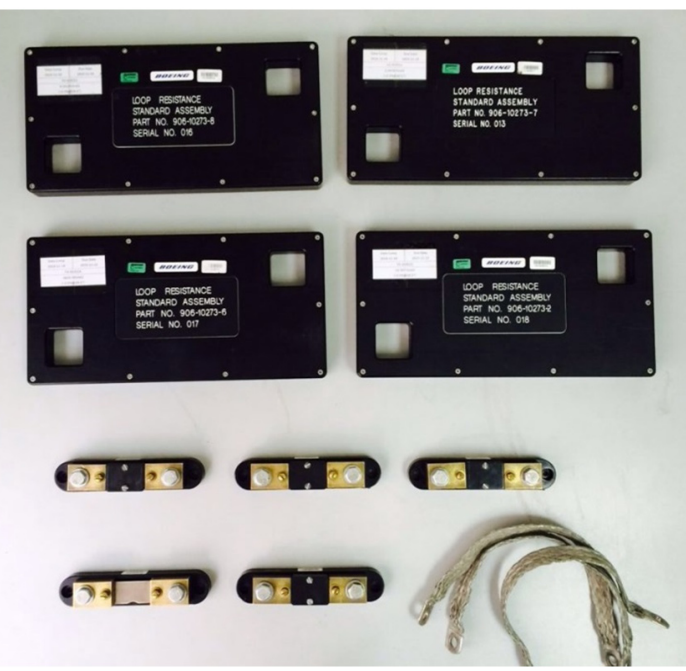

Fig. 7. Standard loop resistors and joint resistors

$$
\delta=\frac{\left|R_{M}-R_{N}\right|}{R_{N}}
$$

In Eq.11, the $\delta$ stands for relative error, $\mathrm{R}_{\mathrm{M}}$ stands for the mean value of the 5 test results for each resistor, $R_{\mathrm{N}}$ stands for the nominal value for each resistor. The relative errors are listed in Table 3.

Table 3. Relative error of loop resistance and joint resistance

\begin{tabular}{|c|c|c|c|}
\hline Loop & $\delta / \%$ & Joint & $\delta / \%$ \\
\hline $\mathrm{R}_{\mathrm{L} 1}$ & $0.70 \%$ & $\mathrm{R}_{\mathrm{J} 1}$ & $1.34 \%$ \\
\hline $\mathrm{R}_{\mathrm{L} 2}$ & $0.45 \%$ & $\mathrm{R}_{\mathrm{J} 2}$ & $1.18 \%$ \\
\hline $\mathrm{R}_{\mathrm{L} 3}$ & $1.43 \%$ & $\mathrm{R}_{\mathrm{J} 3}$ & $0.86 \%$ \\
\hline $\mathrm{R}_{\mathrm{L} 4}$ & $0.07 \%$ & $\mathrm{R}_{\mathrm{J} 4}$ & $0.85 \%$ \\
\hline & & $\mathrm{R}_{\mathrm{J} 5}$ & $1.17 \%$ \\
\hline
\end{tabular}


Theoretically, this test setup is designed to have a $[1 \mathrm{~m} \Omega, 4000 \mathrm{~m} \Omega]$ measurement range, and within full scale the relative error should be smaller than $5 \%$. According to the measurement results, showing in table 1 to table 3 , both of the design objectives have been achieved.

\section{Conclusion}

A new methodology is proposed to evaluate the reliability of the grounding connection by testing both the loop resistance and joint resistance. Compare to the traditional method, the cable is no longer needed to be dissembled any more. A test setup is built to verify the validity, accuracy and test scope of such method. As shown by the experimental results, the measurement range is $[1 \mathrm{~m} \Omega, 4000 \mathrm{~m} \Omega]$, and within full scale the relative error is smaller than $5 \%$.

\section{Acknowledgments}

This work was supported by Seed Foundation of Tianjin University(15ZCZDGX0035) ; The Fundamental Research Funds for The Central Universities (3122015D013); The Fundamental Research Funds for The Central Universities (3122015F002).

\section{References}

1. F. Moupfouma, Aircraft Engin. Aerospace Techn., 4(2),672, 2011.

2. F Rachidi, C A Nucci, M Ianoz, et al. Electromagn. Compatibility IEEE Trans., 38(3), 250, 1996.

3. F Rachidi, C A Nucci, M Ianoz, IEEE Trans. Power Delivery, 14(1),294, 1999.

4. D. Orzan, IEEE Trans.Electromagn. Compatibility, 39(1), 64, 1997.

5. R. Araneo, S. Celozzi S., IEEE Proceedings Scie. Measurem.Techn., 148(2),73, 2001.

6. Y. Watanabe, T. Uchida, Y. Sasaki, et al. Intern.l Symp.Electromagn. Compatibility, Tokyo. IEEE, 2014, p.753.

7. J. Fouladgar, G. Wasselynck, D. Trichet, Ursi Intern. Symp. Electromagn. Theory. 2013, p.104.

8. E.L. Godo, B. Van Deventer, Digital Avionics Systems Conference, 1998. Proceedings., 17th DASC. The AIAA/IEEE/SAE. IEEE, 1998, 1, A25-1-6 vol. 1

9. Liu Y, Lin F, Zhang Q, et al, IEEE Sensors J., 11 (1), 123, 2011.

10. W M C. Sansen,. Analog design essentials, Springer, 2007. 